Derecho \& Realidad

Núm. 24 • II semestre de 2014

Facultad de Derecho y Ciencias Sociales, UPTC

ISSN: 1692-3936

\title{
La responsabilidad internacional del $\epsilon$ stado derivada en la demora en la toma de una decisión judicial. (Alusión al caso García Mateos contra España)
}

\author{
The international responsibility of the State \\ for the delay in a judicial decision making. \\ (Case García Mateos against Spain)
}

Daniel Rigoberto Bernal Gómez*

\section{Resumen}

El presente artículo hace alusión a la conducta que genera eventualmente responsabilidad estatal conforme al derecho internacional, haciendo énfasis en los funcionarios de la rama judicial por la demora en la toma de una decisión definitiva. Posteriormente describe los pormenores de un caso llevado ante el Tribunal Europeo de Derechos Humanos teniendo en la decisión un referente que en materia del acceso a un recurso judicial efectivo debe vincular los Estados en un marco de respeto de los derechos humanos y del acceso a la justicia, sobre todo cuando los jueces actúan de forma lenta y al mismo tiempo no reconocen la búsqueda de una justicia material.

\section{Palabras clave}

Derechos humanos, recurso judicial efectivo, responsabilidad internacional, denegación de justicia, justicia internacional.

* Docente investigador de Derecho Internacional, abogado especialista en Derecho Privado Económico,magíster en Derecho Administrativo. 
Derecho y Realidad

\begin{abstract}
This article refers to conduct that eventually generates State responsibility under international law, with an emphasis on the officials of the judicial branch for the delay in making a final decision. Subsequently describes the details of a case brought before the European Court of Human Rights in the decision taken a benchmark that in terms of access to an effective judicial remedy must link States within a framework of respect for human rights and access to justice, especially when judges act slowly and at the same time they do not recognize the pursuit of material justice.
\end{abstract}

\title{
Keywords
}

Human rights, effective judicial remedy, international responsibility, denial of justice, international justice. 


\section{Introducción}

En derecho internacional de los derechos humanos, uno de los elementos más controversiales es la violación de los mismos por la demora en la toma de una decisión por parte de los jueces de un Estado.

El presente articulo presenta un análisis del Tribunal Europeo de Derechos Humanos, en la demanda al Reino de España por parte de la señora Raquel García Mateos, quien se queja de una vulneración del derecho a un juicio equitativo, especialmente del derecho a la ejecución de las sentencias y del derecho a un recurso efectivo, así como de una discriminación fundada en el sexo, en el marco de un procedimiento referente a la conciliación entre su vida familiar y su vida profesional.

La sentencia hace alusión al derecho a un efectivo recurso, cuya intención es hacer visible que inactividad judicial no es solo no permitir acceso a la justicia, sino que la parsimonia en la toma de la decisión se convierte en denegación de justicia y violación de los derechos humanos.

Primero se debe aclarar que el órgano judicial compromete la responsabilidad internacional del Estado en las mismas condiciones que los demás órganos estatales. Esta es la idea central que domina la materia y que conviene ante todo dejar bien sentada, porque este principio ha sido a veces discutido en Iberoamérica, donde sin razón- se ha querido reservar al órgano judicial un injustificado privilegio.

El extranjero puede comparecer ante las distintas jurisdicciones locales: a) como demandante; b) como demandado, o c) en materia penal, como acusado. En todos estos supuestos la responsabilidad internacional del Estado resulta de la denegación de justicia en su más amplio sentido. Esta noción se aplica a cualquier insuficiencia en la organización o en el ejercicio de la función jurisdiccional que suponga, por parte del Estado, una infracción de su deber internacional de protección judicial.

La responsabilidad en este caso tiene aplicación en la práctica internacional bajo las siguientes hipótesis de caso:

1. Denegación de justicia stricto sensu, es decir, negativa de acceso a los tribunales, caso que se produce cuando un Estado no permite que los extranjeros defiendan sus derechos acudiendo a los tribunales.

2. Defectos en la administración de justicia. El Estado es responsable de su falta de capacidad para asegurar un cierto grado de perfección en su administración de justicia, es decir, para asegurar ese "nivel ordinario requerido por el derecho 
internacional", a que aludía Gladstone ${ }^{1}$. Las principales aplicaciones se refieren a los siguientes casos: a) negativa de dictar sentencia por parte del tribunal; b) cualquier retraso o entorpecimiento inexcusables en la administración de justicia, cuando el extranjero es demandante"; c) a cualquier falta de diligencia en la persecución o en la detención del asesino de un extranjero; d) inversamente, la insólita prisa puesta en juzgar a un acusado extranjero; e) la condena de un extranjero por un tribunal de carácter excepcional, noción que a veces resulta delicado precisar; f) la no ejecución de una sentencia judicial dictada en favor de un extranjero, hecho de similar naturaleza a la amnistía o indulto prematuros del asesino de un extranjero, a su liberación anticipada o a las facilidades que se le hayan dado para su evasión, etcétera.

3. Fallo manifiestamente injusto. Por último, el Estado es responsable de las sentencias "manifiestamente injustas", fórmula jurisprudencial cuya noción es difícil de precisar. Aparece, por ejemplo: a) en el caso de una evidente animosidad contra un extranjero (así, cuando un fallo se funda exclusivamente en razones de malevolencia, a pesar del aparente respeto de las formas exteriores); b) en la hipótesis, difícil de determinar, de una interpretación voluntariamente errónea de la ley local.

Por el contrario, el Estado no es responsable del error judicial de sus tribunales cuando ha sido cometido de buena fe (por ejemplo, al interpretar torcidamente una ley local), pues el Estado no responde de los méritos intrínsecos de la sentencia dictada; de forma que, en términos generales, el error judicial no es causa de responsabilidad internacional, sin embargo, a la luz del derecho internacional, permite eventualmente la revisión de la decisión a petición de las partes.

Al igual que los nacionales, los extranjeros deben apurar los recursos internos contra las resoluciones que les afecten, ya que se presume que dichos recursos son suficientes. El derecho internacional deja a las jurisdicciones nacionales el cuidado de interpretar las leyes internas y sus resoluciones no pueden ser revisadas por una jurisdicción internacional.

La responsabilidad judicial se fundamenta en el sentido de que los jueces y magistrados, al poseer independencia, son responsables en el ejercicio de esta

\footnotetext{
William Ewart Gladstone (Liverpool, 29 de diciembre de 1809 - Hawarden, 19 de mayo de 1898) fue un político liberal británico, primero como diputado en el Parlamento y luego ocupando varios cargos del gobierno de Su Majestad; líder del Partido Liberal (1866-1875 y 1880-1894), fue Primer Ministro del Reino Unido en cuatro ocasiones: de 1868 a 1874, de 1880 a 1885, en 1886, y de 1892 a 1894. Entre sus labores más importantes se destaca la reapertura del ejército y de las universidades, suprimiendo prejuicios religiosos y privilegios económicos. También extendió el sistema de oposiciones para el acceso a la función pública, formó el sistema educativo, y en 1872 introdujo el voto secreto.
} 
potestad jurisdiccional para evitar los mencionados casos, porque gozan de un poder de gran magnitud para la sociedad.

\section{El Tribunal Europeo de Derechos Humanos}

El Tribunal Europeo de Derechos Humanos era el órgano encargado de pronunciarse por medio de una sentencia definitiva y de carácter declarativo, sobre los casos que le fueran elevados por la Comisión, por el Estado demandado o por el Estado del cual el demandante fuera nacional. Después de la entrada en vigor del Protocolo número 9, el particular podía elevar su caso directamente ante el Tribunal y un Comité de jueces (Comité de filtro) decidía si este examinaba o no el caso. Para decidir el caso, contaba con la decisión de la Comisión, que no le vinculaba, en la que quedaban establecidos los hechos y el parecer de la Comisión acerca de la existencia o no de vulneraciones de los derechos invocados. El Tribunal se extinguió al mismo tiempo que la Comisión.

El Tribunal actúa en comités de tres jueces, salas de siete jueces y en dos formaciones de Gran Sala compuestas por 17 jueces (más suplentes) ${ }^{2}$. Las cuestiones administrativas y de organización se discuten en el Pleno del Comité. Las salas se constituyen en el seno de las secciones, término que figura solamente en el Reglamento del Tribunal. A partir del 1 de marzo de 2006, el Tribunal se divide en cinco secciones de nueve jueces cada una, en las que debe haber una composición equilibrada desde un punto de vista tanto geográfico como de representación de sexos, teniendo en cuenta los diferentes sistemas jurídicos existentes en los Estados partes.

En cada sección se constituyen, por periodos de doce meses, comités de tres jueces que constituyen un elemento importante de la nueva estructura, ya que realizan la mayoría de la labor de filtro, a semejanza de la efectuada por la ya desaparecida Comisión. Además se crean salas de siete jueces con tres suplentes. Las salas examinan y deciden la mayoría de las demandas presentadas que no son objeto de una decisión del comité de tres jueces, tanto en lo que se refiere a su admisión como al fondo del asunto. Por último, la Gran Sala que se compone de diecisiete jueces y, al menos, 3 suplentes; en ella, son miembros de oficio el presidente del Tribunal, los dos vicepresidentes, que son también presidentes de dos secciones y los tres presidentes de las otras tres secciones, así como el juez del Estado demandado.

En cuanto a su funcionamiento, ya hemos dicho que el Tribunal solamente se reúne en pleno para decidir materias de tipo administrativo, para la aprobación del

El Pleno del Tribunal elige a su presidente, dos vicepresidentes y tres presidentes de Sección por un periodo de 3 años. 
reglamento interno o para cuestiones electorales ${ }^{3}$. El funcionamiento habitual se realiza a través de las cinco secciones encabezadas por el presidente del Tribunal. Dentro de las secciones, los asuntos son examinados, en cuanto a la admisibilidad y el fondo, por una de las cinco salas de siete jueces, quedando los restantes como sustitutos de los jueces. En cada sección se han establecido tres comités de tres jueces que pueden declarar inadmisible por unanimidad la reclamación individual formulada de acuerdo con el artículo 34 del CEDH con arreglo a los motivos de inadmisibilidad previstos en el artículo 35 del Convenio ${ }^{4}$. El nuevo Tribunal dispone también de dos Grandes Salas de 17 miembros y tres jueces suplentes. Solo algunos casos son examinados por la Gran Sala ya sea por la inhibición de la Sala en cualquier momento del procedimiento antes de dictar sentencia, como por remisión del caso a petición de una de las partes una vez dictada la sentencia de Sala.

El Tribunal tiene una Secretaría permanente compuesta por unas 200 personas de las cuales 100 son letrados organizados en 16 Unidades por razón de criterios lingüísticos y geográficos que realiza una importante labor.

\section{Condiciones de admisibilidad generales}

Previamente al agotar las vías de los recursos internos, tal como se entiende según los principios de derecho internacional generalmente reconocidos. Las condiciones de admisibilidad vienen establecidas en el artículo 35 de la Convención Europea de Derechos Humanos y, solamente a efectos sistemáticos, son las siguientes:

\section{Condiciones formales:}

El agotamiento de los recursos internos encuentra su fundamento en el carácter subsidiario del sistema de protección creado por el Convenio, ya que resulta lógico que los Estados puedan constar con otra posibilidad de corregir las eventuales violaciones de los derechos humanos. Las instituciones nacionales solo deben intervenir en el caso en que un Estado no haya cumplido con esa obligación ${ }^{5}$. No obstante, en ocasiones dicho requisito no se exige, por ejemplo, cuando se retrase en exceso o se demuestre que no es eficaz. Un segundo requisito, es el dejar transcurrir un plazo de seis meses a partir de la notificación de la sentencia definitiva ${ }^{6}$.

Artículo 26 del CEDH.

Artículo 28 del CEDH.

MORTE GÓMEZ, C., Cómo presentar una demanda ante el Tribunal Europeo de los Derechos Humanos, editorial Tirant Lo Blanch, S.L., 2011t., p. 55.

artículo 35.1 del CEDH. 


\section{Condiciones materiales:}

La compatibilidad con el CEDH debe analizarse con base en los siguientes criterios:

Ratione temporis: no cabe exigir responsabilidad internacional a un Estado hasta que este haya ratificado el Convenio o el protocolo de que se trate y se haya verificado su entrada en vigor. En este sentido, habrá de tenerse en cuenta las reservas efectuadas por los Estados en el momento de expresar su consentimiento para quedar vinculados por el Convenio.

Ratione loci: el artículo 1 del Convenio dispone que las Altas Partes Contratantes reconocen a toda persona dependiente de su jurisdicción los derechos y libertades definidos en el Título I ampliando así el concepto de territorio nacional. Sin embargo, en la Decisión de 12 de diciembre de 2001 interpuesta por Bankovic y otros c. 17 Estados miembros del C. de Europa y de la OTAN, la que la Gran Sala estimó que la participación en los bombarderos aéreos de la OTAN en marzo de 1999 sobre Yugoslavia-Kosovo no dio lugar a responsabilidad de los Estados.

Ratione personae: de acuerdo con el artículo 34 del Convenio, cualquier persona física, organización no gubernamental o grupo de particulares que se considere víctima directa de una violación del Convenio o que tenga interés personal puede presentar una demanda contra un Estado parte. El concepto de víctima es independiente de la nacionalidad de la persona. Sin embargo, no caben en el sistema las denominadas "actio popularis", las imputaciones genéricas o en nombre de un grupo indeterminado de la población, sino que, quien alega la vulneración del Convenio debe haber sido directamente afectado por la vulneración que invoca ${ }^{7}$.

-Ratione materiae: son demandas incompatibles por razón de la materia aquellas en las que se plantean alegaciones que se encuentran fuera del ámbito de aplicación del Convenio o de sus protocolos como también en las que existe una falta manifiesta de fundamento de la demanda y las demandas abusivas, esencialmente idénticas o ya sometidas a otras instancias internacionales.

\footnotetext{
En el asunto Conka c. Bélgica, la Liga de Derechos Humanos fue excluida del procedimiento al no ser considerada víctima con ocasión de la detención y expulsión de personas de origen zíngaro de Bélgica hacia Eslovaquia. A juicio del Tribunal, la Liga podía representar a los demandantes junto al abogado designado pero no constituirse ella misma en víctima de las violaciones alegadas, vid. asunto Conka c. Bélgica, $n^{\circ}$ 51564/99, Decisión de 13 de marzo de 2001. Tampoco se reconoció la condición de víctima a los demandantes en el caso Segi y otros y Gestoras por-amnistía y otros c. los 15 Estados de la Unión Europea, n 6422/02 y 9916/02, Decisión de inadmisión de 23 de mayo de 2002.
} 


\section{El caso objeto de análisis}

En esta parte expondré muy brevemente la relación de hechos que dieron como resultado la citada sentencia, así:

1. Raquel García Mateos El día 26 de febrero, basándose en el artículo 37.5 del Estatuto de los Trabajadores de España, la demandante solicitó a su empleador la reducción de jornada de trabajo (con la consiguiente rebaja de sueldo) por razón de la guarda legal de su hijo menor de 6 años. Pidió trabajar media jornada de lunes a miércoles por la tarde de 16,00 a 21,15 horas.

2. El empleador informó a la demandante de su negativa a concederle los horarios solicitados, proponiéndole, a su vez, turnos rotatorios semanales de mañana y tarde de lunes a sábado.

3. El 20 de mayo de 2003, la demandante interpuso ante la jurisdicción de lo social, el procedimiento especial en materia de ajuste de la jornada de trabajo por razón de guarda legal de niño menor de 6 años. Mediante sentencia de 25 de septiembre de 2003, el Juez de lo social $n^{\circ} 1$ de Madrid, desestimó la demanda, considerando que la jornada de trabajo reducida debía de encuadrarse en el marco de la jornada de trabajo ordinaria, mientras que la demandante solicitaba la exclusión de varios días laborables (de jueves a sábado) y la supresión total de los turnos rotatorios, lo cual implicaba, no una reducción de jornada, sino una modificación de esta última.

4. El 6 de noviembre de 2003, la demandante presentó ante el Tribunal Constitucional un recurso de amparo fundamentándolo en el derecho a un proceso equitativo y en el principio de no discriminación basado en el sexo. Mediante sentencia del 15 de enero de 2007, el Alto Tribunal estimó el recurso, considerando que el principio de no discriminación por razón de sexo había sido vulnerado al respecto. El Tribunal Constitucional se refirió a la jurisprudencia constante del TEDH según la cual "el derecho comunitario se opone a la aplicación de una medida nacional que, aunque esté formulada de manera neutra perjudica a un porcentaje muy superior de mujeres que de hombres, a menos que la medida controvertida esté justificada por factores objetivos ajenos a cualquier discriminación por razón de sexo", y hace observar que "en el caso de una discriminación indirecta, no se exige aportar como término de comparación la existencia de un trato más beneficioso atribuido única y exclusivamente a los varones; basta, que exista, en primer lugar, una norma o interpretación o aplicación de la misma que produzca efectos desfavorables para un grupo formado mayoritariamente por trabajadoras femeninas”. El Tribunal Constitucional falló que hubo violación del principio de no discriminación por razón de sexo, debido a que "la negativa del órgano judicial a reconocer a la trabajadora la concreta reducción de jornada 
solicitada, sin analizar en qué medida dicha reducción resultaba necesaria para la atención a los fines de relevancia constitucional a los que la institución sirve ni cuáles fueran las dificultades organizativas que su reconocimiento pudiera causar a la empresa, se convierte, así, en un obstáculo injustificado para la permanencia en el empleo de la trabajadora y para la compatibilidad de su vida profesional con su vida familiar, y en tal sentido, constituye una discriminación indirecta por razón de sexo". Por consiguiente, el Alto Tribunal concedió el amparo a la demandante y anuló la sentencia del 25 de septiembre de 2003 dictada por el Juzgado de lo social $\mathrm{n}^{\mathrm{0}} 1$ de Madrid, ordenándole dictar una nueva sentencia, acorde con el derecho fundamental encausado.

5. Mediante nueva sentencia de fecha 6 de septiembre de 2007, el Juzgado de lo social $n^{0} 1$ desestimó la demanda. El juez consideró que la reducción de la jornada de trabajo solicitada por la demandante quedaba fuera del marco fijado en el artículo 37 del Estatuto de los Trabajadores, en lo referente a su petición de no trabajar los jueves, viernes y sábados, días que forman parte de la jornada ordinaria de trabajo y entre los cuales, dos de ellos, a saber los viernes y los sábados corresponden a los días de mayor afluencia de clientes. El juez estimó, además, que la demandante no había justificado suficientemente la necesidad al objeto de la protección constitucional que le había sido concedida, de que la reducción solicitada rebasara los límites de un mero ajuste de la jornada de trabajo, propiamente dicha

6. El 28 de noviembre de 2007, la demandante presentó un nuevo recurso de amparo, que el Alto Tribunal examinó como procedimiento de ejecución de su sentencia dictada el 15 de enero de 2007. El 29 de octubre de 2008, la demandante informó al Tribunal Constitucional que su hijo, entretanto, había alcanzado la edad de seis años, de manera que debido a la duración del procedimiento judicial, ya no podía beneficiarse del derecho a la reducción de la jornada de trabajo que había reclamado para cuidar a su hijo. No pudiendo por tanto ejecutarse la sentencia del Tribunal Constitucional en sus propios términos, la demandante reclamó, a título alternativo, y amparándose en el artículo 18.2 de la Ley Orgánica del Poder judicial, una indemnización.

6. Mediante decisión motivada del 12 de enero de 2009, el Tribunal Constitucional consideró que su sentencia de 15 de enero de 2007 no se había ejecutado correctamente, y declaró nula la sentencia del 6 de septiembre de 2007, del Juzgado de lo social $n^{0} 1$ de Madrid. Estimó, sin embargo, que no era necesario reenviar el caso al juez a quo en la medida en que un nuevo juicio del Juzgado de lo Social, no tendría ningún sentido, dada la edad del hijo de la demandante, y consideró que la fijación de una indemnización alternativa no estaba permitida por el artículo 92 de la Ley Orgánica del Tribunal Constitucional. 


\section{Sobre la admisibilidad de la demanda ante el TEDH}

La demandante manifestó que se violó su derecho a un proceso equitativo dentro de un plazo razonable, y el principio de no discriminación por razón de sexo, por no haber obtenido reparación de la vulneración de su derecho fundamental y estimó que no ha gozado de un recurso efectivo ante el Tribunal Constitucional.

El Gobierno español alegó que no se han agotado las vías de los recursos internos en lo referente a la pretensión indemnizadora de la demandante ante el Tribunal Constitucional, en los siguientes términos:

1. Alega que el Tribunal Constitucional no ha podido analizar la pertinencia de la concesión de la indemnización reclamada, en la medida en que la Ley Orgánica reguladora se lo prohíbe.

2. La demandante hubiera debido presentar una demanda de indemnización ante el Ministerio de Justicia, fundándola en un error judicial o en un funcionamiento anormal de la justicia.

3. El Gobierno recuerda que cuando un Estado tiene instituido un recurso indemnizador, el TEDH debe concederle un mayor margen de valoración con el fin de que pueda regular este recurso interno, de manera coherente con su propio sistema jurídico y sus tradiciones, de conformidad con el nivel de vida del país ${ }^{8}$.

4. En cuanto a la existencia de perspectivas de éxito del tal recurso para la demandante, el Gobierno en prueba de ello señala que el funcionamiento anormal de la justicia ya ha sido reconocido en el ámbito del derecho a un proceso equitativo dentro de un plazo razonable; también lo ha sido en conceder una reparación vinculada al principio de la presunción de inocencia, al carecer de un sistema indemnizador por detención provisional, en caso de absolución.

5. Por otra parte, el Tribunal Supremo también ha reconocido el error judicial en el caso de un Tribunal que había estimado el recurso de un extranjero contra la imposición de una sanción por carecer de permiso de trabajo, mientras desestimaba los de otros extranjeros que se encontraban en situaciones similares, sin explicar los motivos de su decisión.

El Gobierno señaló, además, que España posee en la Ley de Procedimiento Laboral, una acción tendente a la protección de los derechos fundamentales incluyendo, especialmente, "La igualdad de trato entre mujeres y hombres", consiguiendo que el juez se pronuncie sobre la cuantía de la indemnización que corresponda. Se trata de un procedimiento rápido y prioritario, que es el que hubiera debido de entablar

(Scordino c. Italia (no 1) [GC], no 36813/97, § 189, TEDH 2006-V). 
la demandante tras la decisión del Tribunal Constitucional, constatando la no ejecución de la primera sentencia.

Como respuesta en sus observaciones, la demandante mantiene que ha presentado dos recursos ante el Tribunal Constitucional, último garante de los derechos fundamentales, sin obtener satisfacción ni compensación, y sin que se le ofreciera otra opción que la de la declaración de nulidad de las decisiones judiciales a quo.

\section{Análisis del TEDH sobre la admisión de la demanda}

La regla del agotamiento previo de las vías de recurso internas impone a todo demandante la obligación de utilizar, en primer lugar, los recursos normalmente disponibles y suficientes dentro del orden jurídico interno, que le permitan obtener reparación de las violaciones que alega, antes de que estas alegaciones sean sometidas al Tribunal Europeo de Derechos humanos ${ }^{9}$. Esta regla constituye un aspecto importante del principio tendente a que el mecanismo de salvaguarda instaurado revista un carácter subsidiario en relación con los sistemas nacionales de garantía de los derechos humanos ${ }^{10}$. Se basa en el supuesto, comprendido en el artículo 13 (con el que presenta estrechas afinidades), que el orden interno ofrece un recurso efectivo en cuanto a la violación alegada ${ }^{11}$.

Sin embargo, el TEDH ha señalado que debe aplicar esta regla, teniendo en cuenta el contexto, dándole flexibilidad a la regla del agotamiento previo de las vías de recurso internas, ya que, en palabras del tribunal, no se ajusta a una aplicación automática y no reviste un carácter absoluto; al controlar el respeto, se deben tener en cuenta las circunstancias de la causa ${ }^{12}$.

El TEDH estima que, habida cuenta de las circunstancias del caso, hubiera sido excesivo pedir a la demandante que entablara el recurso mencionado por el Gobierno, más aun, cuando no ha citado como ejemplo ningún caso en el que alguna persona, en una situación análoga, hubiera obtenido una reparación adecuada, en la cual se reconocieran unos hechos similares como casos de funcionamiento anormal de la justicia o de error judicial.

Respecto del procedimiento previsto indicado por el Gobierno español, el TEDH señala que la demandante acudió al Tribunal Constitucional solicitando el amparo

\footnotetext{
Selmouni c. Francia [GC], n² 25803/94, § 74, TEDH 1999-V

10 (Akdivar y otros c. Turquía, 16 de septiembre de 1996, § 65, Recopilación de sentencias y decisiones 1996-IV

$11 \mathrm{Kud}^{3}$ a c. Polonia [GC], n 30210/96, § 152, TEDH 2000-XI y Scordino (no 1) [GC]

12 Van Oosterwijck c. Bélgica, 6 de noviembre de 1980, § 35, serie A n 40.
} 
que le fue concedido. El Gobierno no puede pretender que esta vía de recurso para lograr la constatación de la vulneración del principio de no discriminación sea insuficiente hasta el punto de obligarla a entablar un nuevo procedimiento, cuyo objetivo principal sería también lograr la misma constatación de la vulneración. A este respecto, el TEDH recuerda que cuando una vía de recurso ha sido utilizada, no se exige el uso de otra vía, cuyo objetivo sería prácticamente el mismo.

En definitiva, el TEDH estima que no se le puede reprochar a la demandante el no haber tomado otras vías de recurso, cuando incluso la que ha seguido se ha revelado ineficaz tras seis años de procedimiento ${ }^{13}$.

\section{Sobre las violaciones alegadas}

\section{Discriminación por razón de sexo}

La demandante alegó que su derecho a un proceso equitativo dentro de un plazo razonable, ha sido infringido y estima que la prohibición de discriminación por razón de sexo ha sido vulnerada en lo que a ella respecta. Alega no haber obtenido reparación de la violación de su derecho fundamental, constatado por el Tribunal Constitucional ${ }^{14}$. El Gobierno español se opone a esta tesis.

\section{Argumentos de las partes}

España alega que en la sentencia de 15 de enero de 2007, el Tribunal Constitucional estimó la demanda de la demandante y le acordó el amparo en lo referente a su queja relativa al principio de no discriminación, aunque, con base en el hecho de que su hijo ya había cumplido la edad máxima para la cual este derecho estaba previsto, cuando el procedimiento de ejecución estaba pendiente ante el Tribunal Constitucional, no pudo disfrutar de la reducción de la jornada de trabajo reclamada. La imposibilidad material de ejecutar la sentencia del Tribunal Constitucional no constituye en el presente caso una violación del derecho a la equidad del procedimiento, no hay resistencia de la Administración a la obligación de ejecutar una decisión judicial.

13 mutatis mutandis, Schrepler c. Rumanía, n²2626/02, § 37, 15 de marzo de 2007, y Constantin Oprea c. Rumanía, $n^{\circ} 24724 / 03, \S 41,8$ de noviembre de 2007

14 Convención Europea de protección de Derechos humanos: Artículo 6 "1. Toda persona tiene derecho a que su causa sea oída equitativamente (...) y dentro de un plazo razonable, por un Tribunal (...) que decidirá los litigios sobre sus derechos y obligaciones de carácter civil (...)." Artículo 14 "El goce de los derechos y libertades reconocidos en el (...) Convenio ha de ser asegurado sin distinción alguna, especialmente por razones de sexo, raza, color, lengua, religión, opiniones políticas u otras, origen nacional o social, pertenencia a una minoría nacional, fortuna, nacimiento o cualquier otra situación." 
Respecto de la infracción al principio de no discriminación, España apunta que ha sido reconocida y reparada por el Tribunal Constitucional. Ahora bien, el principio de subsidiaridad se opone, según su opinión, a que el TEDH analice la violación alegada de un derecho cuya violación ya ha sido constatada por las jurisdicciones internas.

La señora Raquel García Mateos estima, por su parte, que habiendo sido declarada nula por el Tribunal Constitucional la sentencia del Juzgado de lo Social $\mathrm{n}^{\mathrm{o}} 1 \mathrm{de}$ Madrid, ningún otro Tribunal ha examinado la procedencia de su reclamación y considera que el hecho de que el Tribunal Constitucional haya declarado nulas las sentencias dictadas por el Juzgado de lo Social $\mathrm{n}^{\circ} 1$ de Madrid, no significa que se haya respetado el artículo 6 del Convenio.

\section{Valoración del TEDH}

El derecho a un proceso equitativo no puede obligar a que un Estado ejecute cada sentencia de carácter civil, cualquiera que sea y cualesquiera que sean las circunstancias $^{15}$. En el presente caso, se trataba de ejecutar la sentencia del Tribunal Constitucional de 15 de enero de 2007, quien, después de haber resuelto que hubo violación del principio de no discriminación por razón de sexo, anulaba la sentencia del 25 de septiembre de 2003 dictada por el Juzgado de lo Social $\mathrm{n}^{\mathrm{o}} 1$ de Madrid y le ordenaba dictar una nueva que fuera respetuosa con el derecho fundamental.

Pese a ello el Juzgado de lo Social $\mathrm{n}^{\mathrm{o}} 1$ de Madrid no ha dado a la sentencia de 15 de enero de 2007 del Tribunal Constitucional, el curso adecuado. Mediante una segunda sentencia de 6 de septiembre de 2007, el Juzgado de lo Social $n^{0} 1$ consideró que la petición de reducción de jornada solicitada por la demandante, excedía los límites autorizados legalmente y que no había justificado suficientemente la necesidad. La demandante se vio entonces constreñida a acudir nuevamente al Tribunal Constitucional. Este último consideró, en su decisión del 12 de enero de 2009, que su sentencia del 15 de enero de 2007 se había ejecutado incorrectamente, y declaró nula, a su vez, la segunda sentencia del Juez de lo Social $\mathrm{n}^{\mathrm{o}} 1$ de Madrid.

Los Estados tienen la obligación de poner a disposición de los demandantes, un sistema que les permita lograr la ejecución correcta de las decisiones dictadas por las jurisdicciones internas. Tiene como tarea, examinar si las medidas adoptadas por las autoridades nacionales -en este caso, una autoridad judicial- a los efectos de la ejecución de las decisiones en cuestión, han sido adecuadas y suficientes ${ }^{16}$, ya que, cuando dichas autoridades tienen la obligación de actuar para ejecutar una decisión judicial y omiten hacerlo -o lo hacen incorrectamente- comprometen la responsabilidad de los Estados.

15 (Sanglier c. Francia, $n^{\circ}$ 50342/99, § 39, 27 de mayo de 2003)

16 Ruianu c. Rumanía, $n^{\circ} 34647 / 97, \S 66,17$ de junio de 2003 
El TEDH señaló en el presente caso que el Tribunal Constitucional, mediante su decisión del 12 de enero de 2009, resolvió que se había infringido el derecho de la demandante a la ejecución de su primera sentencia que reconocía la violación del principio de no discriminación. Al respecto una decisión o medida favorable al demandante no basta, en principio, para retirarle su condición de "víctima", a menos que las autoridades nacionales hayan reconocido, explícitamente o en substancia, y reparado posteriormente la violación ${ }^{17}$. No obstante las dos sentencias dictadas por el Tribunal Constitucional, la violación constatada por el más Alto Tribunal no ha sido reparada al día de hoy.

La intención inicial de la demandante no era la de conseguir una indemnización, sino la de ver reconocido su derecho a una jornada de trabajo reducida con el fin de poder cuidar a su hijo antes de que cumpliera los seis años de edad. Fue más adelante, al sobrepasar su hijo la edad legalmente prevista para que se hubiera podido beneficiar de la reducción de su jornada de trabajo, cuando formuló su demanda de indemnización.

En su decisión del 12 de enero de 2009, el Tribunal Constitucional rechazó conceder una indemnización a la demandante a este respecto, y no le dio indicación alguna sobre alguna eventual posibilidad de reclamación posterior ante otro órgano administrativo o judicial.

Cierto es que debido a la edad del niño al término del procedimiento, una restitución en la integridad del derecho de la demandante, considerado vulnerado, no era ya posible. El TEDH no puede indicar al Estado demandado la manera en la cual el régimen de reparaciones, en el ámbito del recurso de amparo, debería ser instituido. Solamente constata que la protección concedida por el Tribunal Constitucional se ha mostrado ineficaz ${ }^{18}$. La no restitución en la integridad del derecho de la demandante ha hecho baldía la protección acordada por la concesión del amparo por parte del Tribunal Constitucional y por ello hay violación al Convenio de Derechos Humanos, artículos 6 y 14.

17 Brumãrescu c. Rumanía [GC], $n^{\circ}$ 28342/95, § 50, TEDH 1999-VII, Scordino (no 1) [GC]

18 Por una parte la demanda de ajuste de la jornada de trabajo presentada por la demandante ante el Juzgado de lo Social $n^{\circ} 1$ no obtuvo respuesta en cuanto al fondo, a pesar del hecho de que las dos sentencias en sentido contrario del Juez de lo Social habían sido declaradas nulas. Por otra parte, el recurso de amparo presentado por la demandante ante el Tribunal Constitucional ha perdido su funcionalidad al haber considerado el Tribunal Constitucional que el artículo $55 \S 1$ de la Ley Orgánica del Tribunal Constitucional no prevé la concesión de indemnización como medio de reparación de una violación de un derecho fundamental. 


\section{Derecho a la concesión de un recurso efectivo ante una instancia nacional}

\section{Argumentos de las partes}

La demandante Raquel García Mateos denuncia una vulneración del artículo 13 del Convenio y estima no haber disfrutado de un recurso efectivo en la medida en que el Tribunal Constitucional no ha procedido a la reparación de la vulneración del principio de no discriminación por razón de sexo, que él mismo había constatado ${ }^{19}$.

España estimó que la demandante no demostró que el Tribunal Constitucional haya menoscabado el derecho protegido por el artículo 13 del Convenio. Subrayó que la Ley Orgánica del Tribunal Constitucional no prevé indemnización a raíz de la constatación de una violación de un derecho fundamental. Alegó que la fijación de tal indemnización competería a las jurisdicciones ordinarias. Incluso suponiendo que el Tribunal Constitucional estuviera en el origen de la violación de un derecho fundamental ${ }^{20}$.

\section{Valoración del TEDH}

El TEDH estima que la queja planteada por la demandante en el ámbito del artículo 13 concierne los mismos hechos que se analizaron desde la perspectiva del artículo 6 del Convenio y recuerda que las exigencias del artículo 13, en el presente caso, son menos estrictas que las del artículo 6 , y se subsumen en estas últimas ${ }^{21}$.

En consecuencia, el TEDH estima que no procede analizar si ha habido en el presente caso violación del artículo 13 del Convenio.

\section{La decisión}

En este caso el Estado español fue condenado por el TEDH, en aplicación del artículo 41 del Convenio para la Protección de los Derechos Humanos y de las Libertades Fundamentales: "Si el Tribunal declara que ha habido violación del Convenio o de sus Protocolos y si el derecho interno de la Alta Parte Contratante

19 Art. 13 "Toda persona cuyos derechos y libertades reconocidos en el (...) Convenio hayan sido violados, tiene derecho a la concesión de un recurso efectivo ante una instancia nacional (...)."

20 Ley 30/1992 de 26 de noviembre de 1992 de Régimen Jurídico de las Administraciones Públicas y del Procedimiento Administrativo Común, prevé, en su artículo139 (párrafo 21 más arriba) que, en caso de reconocimiento de una violación por parte del mismo Tribunal Constitucional, la fijación de una indemnización competería, en cualquier caso, al Consejo de Ministros, y no al propio Tribunal Constitucional.

21 (Kamasinski c. Austria, 19 de diciembre de 1989, $§ 110$, serie $\left.A n^{\circ} 168\right)$. 
Derecho y Realidad

sólo permite de manera imperfecta reparar las consecuencias de dicha violación, el Tribunal concederá a la parte perjudicada, si así procede, una satisfacción equitativa."

\section{Daños}

La demandante reclama 40.986 euros en concepto de daño moral que habría sufrido. Este importe corresponde a la reclamación presentada ante el Tribunal Constitucional español.

El TEDH considera que procede otorgar a la demandante, la cantidad de 16.000 euros, en concepto de daño moral.

\section{Gastos y costas}

La demandante solicita 5.760 euros para resarcirse de los gastos y costas devengados ante el TEDH, cantidad que corresponde a un $12 \%$ del importe reclamado en concepto de daño moral, pero no presenta minuta de honorarios.

\section{Intereses por mora}

El Tribunal juzga conveniente imponer el mismo tipo de interés por mora que el tipo de interés de la facilidad marginal de crédito del Banco Central Europeo más tres puntos en porcentaje.

Manifiesta el TEDH que el Estado demandado es responsable y debe abonar al demandante, dentro de los tres meses siguientes al día en que la sentencia haya adquirido carácter de firmeza, 16.000 euros (dieciséis mil euros) más cualquier importe que se pueda devengar en concepto de tributos, por daño moral; que a partir de la expiración de dicho plazo, y hasta el momento del pago. Estos importes serán incrementados del interés simple de un tipo igual al de la facilidad marginal de crédito del Banco Central Europeo aplicable durante este período, más tres puntos de porcentaje

\section{Conclusión}

La lección comienza a entenderse con relación a la aplicación de una justicia pronta por parte de las organizaciones internacionales. La presente demanda contra el Estado español no es más que la evidencia de que si no hay una justicia pronta, esto equivale a una denegación de justicia.

En derecho internacional, la responsabilidad internacional desafortunadamente no tiene un instrumento jurídico que permita reconocer de manera puntual la falta de 
diligencia en el proceso judicial, que a lo sumo solo queda en reproches disciplinarios internos a un juez, que en actitud racional manifiesta y salva su responsabilidad argumentando que la cantidad de trabajo no le permite conocer de manera rápida un asunto ordinario.

Estos elementos son precisamente los que deben terminar. El Estado debe entender que si no cumple una función judicial de manera efectiva en la protección de derechos, él mismo se hace responsable por esa situación y debe entrar a reparar, y la prueba de ello está en el referente jurisprudencial analizado.

Este referente debe ser tenido en cuenta por el sistema interamericano de derechos humanos, dada la frecuencia en que los Estados americanos incurren en demoras injustificables en la toma de una decisión judicial, y debe abrir un espacio hacia el reconocimiento de responsabilidad en la lenta administración de justicia, especialmente de algunos países latinoamericanos.

\section{Referencias}

Convenio para la Protección de los Derechos Humanos y de las Libertades Fundamentales.

Ley 30 de 1992 de 26 de noviembre de Régimen Jurídico de las Administraciones Públicas y del Procedimiento Administrativo Común, España.

Ley Orgánica del Tribunal Constitucional Español.

Morte, C. (2011). Cómo presentar una demanda ante el Tribunal Europeo de los Derechos Humanos. Barcelona: Tirant Lo Blanch.

Tribunal Europeo de Derechos Humanos (2000). Kud³a c. Polonia [GC], n 30210/ 96.

Tribunal Europeo de Derechos Humanos (17 de junio de 2003). Ruianu c. Rumanía, $n^{0} 34647 / 97, \S 66$.

Tribunal Europeo de Derechos Humanos (6 de noviembre de 1980). Van Oosterwijck c. Bélgica.

Tribunal Europeo de Derechos Humanos (16 de septiembre de 1996). Akdivar y otros c. Turquía.

Tribunal Europeo de Derechos Humanos (1999). Brumãrescu c. Rumanía [GC], $n^{0} 28342 / 95$. 
192

Derecho \& Realidad

Tribunal Europeo de Derechos Humanos (13 de marzo de 2001). Conka c. Bélgica, $\mathrm{n}^{\circ} 51564 / 99$.

Tribunal Europeo de Derechos Humanos (8 de noviembre de 2007). Constantin Oprea c. Rumanía, no 24724/03.

Tribunal Europeo de Derechos Humanos (19 de diciembre de 1989). Kamasinski c. Austria.

Tribunal Europeo de Derechos Humanos (27 de mayo de 2003). Sanglier c. Francia, $n^{0} 50342 / 99, \S 39$.

Tribunal Europeo de Derechos Humanos (15 de marzo de 2007). Schrepler c. Rumanía, no 22626/02.

Tribunal Europeo de Derechos Humanos (2006). Scordino c. Italia (no 1) [GC], $n^{0} 36813 / 97$.

Tribunal Europeo de Derechos Humanos (1999). Selmouni c. Francia [GC], no $25803 / 94$. 